\title{
The effect of exercises and insoles on the feet in leprosy patients
}

\author{
O efeito de exercicios e palmilhas nos pés de pacientes com hanseniase \\ El efecto de ejercicios y de plantillas en los pies de pacientes con lepra \\ Carolina Ribeiro do Prado', Leonardo Cesar Carvalho², Eliane Oliveira Guarda 3 , Christiane Borges Abrão Santos 4 , \\ Wendel Antônio Fagundes ${ }^{5}$, Denise Hollanda lunes ${ }^{6}$
}

\begin{abstract}
I The purpose of this study is to analyze the effects of using customized insoles and leg and foot exercises on the feet of patients with neuropathy caused by leprosy. Thirty volunteers diagnosed with leprosy were assigned to one of three groups: (1) Exercise group ( $n=10$ ): performed exercises for the intrinsic muscles of the foot; (2) Insole group $(n=10)$ : used insoles to correct foot positioning; (3) Insole and Exercise group ( $n=10)$ : used insoles and performed an exercise routine. The results of the treatments were analyzed with photogrammetry using the Alcimagem ${ }^{\circledR}$ and AutoCAD ${ }^{\circledR}$ programs. Left hindfoot posture changed after treatment in the Exercise and Insole groups (hindfoot, pre versus post $<0.001$ ). We also found that combining exercise and insoles did not alter the alignment of the feet during the study's evaluation period (customized insoles and exercises, pre versus post $<0.05$ ), which suggests that follow-up for more than four months may be needed. The left hindfoot's alignment can be changed with supervised exercises and the use of insoles.
\end{abstract}

Keywords I Leprosy; Orthotic Devices; Exercise; Photogrammetry; Rehabilitation.

RESUMO I O objetivo deste estudo é analisar a influência do uso de palmilhas personalizadas e exercícios para perna e pés nos ângulos do antepé, retropé e arco plantar de pacientes com neuropatia causada por hanseníase. Trinta voluntários diagnosticados com hanseníase foram designados para um dos três grupos: (1) grupo exercício $(n=10)$ : realização de exercícios para pernas e pés; (2) grupo palmilha $(n=10)$ : utilização de palmilhas para corrigir o posicionamento do pé; (3) grupo palmilha e exercícios ( $n=10$ ): uso de palmilhas associado a uma rotina de exercícios. O resultado dos tratamentos foi analisado por meio de fotogrametria, com os softwares Alcimagem e AutoCAD. A postura do retropé esquerdo foi modificada após o tratamento no "grupo exercício" e "grupo palmilha" (retropé, pré versus pós<0,001). Também foi observado que a combinação entre exercícios e palmilhas não alterou o alinhamento dos pés durante o período de avaliação do estudo (palmilha e exercícios, pré versus pós>0,05), o que sugere que o acompanhamento por mais de quatro meses pode ser necessário. Assim, o uso isolado de exercícios supervisionados ou de palmilhas altera o alinhamento do retropé, como aferido por fotogrametria.

Descritores | Hanseníase; Aparelhos Ortopédicos; Exercícios; Fotogrametria; Reabilitação.

RESUMEN | El presente estudio tiene como objetivo analizar la influencia del uso de plantillas personalizadas y la práctica ejercicios de piernas y pies en los ángulos del antepié, del

\footnotetext{
The study was developed at the health system of the city of Alfenas (MG), Brazil. Its partial results were presented at the 3rd Brazilian Symposium of Hansenology and in a Scientific Initiation Seminar at Unifenas.

Universidade José do Rosário Vellano (Unifenas) - Alfenas (MG), Brazil. E-mail: carolinarprado@yahoo.com.br. Orcid: 0000-0002-3558-5876

Universidade Federal de Alfenas (Unifal) - Alfenas (MG), Brazil. E-mail: leonardo.carvalho@unifal-mg.edu.br. Orcid: 0000-0001-6511-8315

3Universidade José do Rosário Vellano (Unifenas) - Alfenas (MG), Brazil. E-mail: grupooliveira.eliane@gmail.com. Orcid: 0000-0002-9622-9760

${ }^{4}$ Universidade José do Rosário Vellano (Unifenas) - Alfenas (MG), Brazil. E-mail: chrisabrao@yahoo.com.br. Orcid: 0000-0003-2274-9533

${ }^{5}$ Prefeitura de Alfenas - Alfenas (MG), Brazil. E-mail: wendel@alfenas.mg.gov.br. Orcid: 0000-0002-8967-0793

${ }^{6}$ Universidade Federal de Alfenas (Unifal) - Alfenas (MG), Brazil. E-mail: deniseiunes@unifal-mg.edu.br. Orcid: 0000-0003-1396-9980
} 
retropié y del arco plantar de pacientes con neuropatía debido a lepra. Treinta voluntarios diagnosticados con lepra fueron asignados a uno de estos tres grupos: (1) grupo de ejercicios $(n=10)$ : hacer ejercicios de piernas y pies; (2) grupo de plantillas $(n=10)$ : utilizar plantillas para corregir la posición del pie; (3) grupo de plantillas y ejercicios $(n=10)$ : utilizar plantillas asociadas con una rutina de ejercicios. Los resultados de los tratamientos se analizaron mediante fotogrametría, con los softwares Alcimagem y AutoCAD. La postura del retropié izquierdo se modificó tras el tratamiento en el "grupo de ejercicios" y en el "grupo de plantillas" (retropié, pre versus pos <0,001). También se observó que la combinación de ejercicios y plantillas no alteró la alineación del pie durante el período de evaluación del estudio (plantilla y ejercicios, pre versus pos $>0,05$ ), lo que sugiere que puede requerirse seguimiento durante más de cuatro meses. Por lo tanto, la práctica aislada de ejercicios supervisados o el uso de plantillas altera la alineación del retropié, medido por fotogrametría. Palablas clave I Lepra; Aparatos Ortopédicos; Ejercicio; Fotogrametría; Rehabilitación.

\section{INTRODUCTION}

Leprosy is still a major public health problem in Brazil $^{1}$, despite the reduction in the number of patients registered for treatment, and new cases are still being diagnosed ${ }^{2}$. According to the World Health Organization (WHO), there were 176,176 cases at the end of 2015 and 26,395 new cases of leprosy detected in $2015^{3}$, indicating high endemicity of the disease, especially in the North, Northeast and Midwest regions of the country ${ }^{2,4}$. Brazil is second in the world, behind India, in terms of absolute numbers of cases, with $1.51 / 10,000$ in $2012^{4}$, considered a very high detection rate ${ }^{1}$.

Mycobacterium leprae ( $M$. leprae) is immunologically specific to the skin and peripheral nerves. Globally, leprosy is still the most common cause of treatable neuropathy ${ }^{5}$. Dysfunction of peripheral nerves can result in sensory, motor, and autonomic changes, and can cause skin rashes, muscle contractures, and deformities of fingers associated with distal bone absorption ${ }^{6}$. The combination of loss of sensation and biomechanical changes resulting from leprosy makes the foot vulnerable to pressures and trauma ${ }^{6-8}$.

In the presence of the disease, the feet may undergo classical biomechanical alterations, which are associated with weakness of the anterior tibial, posterior tibial and fibular muscles ${ }^{6,9}$. The presence of these weak muscles in the regions of the forefoot, hindfoot and midfoot produces alignment alterations, due to the fall of the transverse arch and the exposure of the heads of the metatarsal bones, in addition to claw fingers. These changes favor the onset of ulcerations and calluses due to excess local pressure ${ }^{6,9}$.

The formation of calluses, blisters, and ulcers can be complicated by cellulitis and osteomyelitis, and may eventually result in amputations, which are the leading cause of disability in this population ${ }^{7}$.
After a diagnosis of leprosy, drug treatment should be administered alongside a program for prevention of physical disability ${ }^{5}$. This program should consist of several preventive measures, including guidance on the self-care of the feet ${ }^{3,9}$, exercise guidelines for hands, eyes and feet to be performed at home ${ }^{9}$, and provision of ethyl vinyl acetate (EVA) insoles, which can be used to decrease plantar pressure points ${ }^{3}$.

The purpose of insoles is to distribute vertical forces to reduce peak pressure on areas of the $\operatorname{sole}^{10}$. Free distribution of insoles is part of the disability-prevention program instituted by the Brazilian Ministry of Health, which prioritizes access to services in all regions of the country where leprosy is endemic. There are reports that the free distribution of adapted shoes reduces diseasetreatment costs in developing countries ${ }^{11}$. Foot problems in those with leprosy are compared to those found in diabetics ${ }^{12}$. The two diseases cause incapacities related to the peripheral nerve's dysfunction. Although the diseases have different causes, the mechanical factors affecting the foot are very similar, as are the interventions including foot care and footwear programs ${ }^{11,13}$.

Despite the fact custom orthotics are often prescribed to prevent plantar ulcers, there are few reports on the use of insoles for treating neuropathic leprous feet ${ }^{13}$.

Exercises are commonly used to prevent foot complications in cases of diabetes and ankle sprain ${ }^{14}$. There are reports on the use of exercises in the treatment of leprosy patients to prevent contractures of paralyzed hands and paralyzed eyelids ${ }^{15}$. The Ministry of Health, in its Incapacities manual, presents some exercises patients should be instructed to perform at home ${ }^{9}$. These exercises involve stretching of the sural triceps, active and resisted exercises for inversion, eversion, dorsiflexion and plantar flexion, and resistance exercises for the intrinsic musculature of the feet. Reports about the isolated use 
of exercises or insoles associated with the use of the two resources to promote biomechanical changes in the feet in leprosy patients are still scarce.

Thus, the aim of the study was to analyze the influence of using exercises for feet and legs and customized insoles at the angles of the forefoot, hindfoot and plantar arch on patients with neuropathic feet caused by leprosy measured with photogrammetry.

\section{METHODOLOGY}

\section{Participants}

This quasi-experimental study was conducted with a population of 47 volunteers diagnosed with leprosy, in the Health System of the city of Alfenas, from January 2009 to December 2013. The inclusion criteria were any clinical category of leprosy; usage of the municipal health service for treatment of the feet, with or without sensory deficits, including reaction episodes; and willingness to participate in the research. The exclusion criteria were the presence of motor disorders, amputations, diabetes, alcoholism, and HIV or syphilis. The two first criteria were set because the patients could not perform foot exercises, and the other conditions were selected because they could lead to neurological impairments. Thirtysix patients met the inclusion criteria and agreed to participate. The volunteers were divided into three groups and allocated by convenience. Six volunteers who did not complete the full number of treatment sessions were excluded from the analysis, so the final sample consisted of 30 volunteers divided into three groups (Figure 1). The Exercise group $(n=10)$ followed an exercise protocol (Chart 1$)$, the Insole group ( $n=10)$ used custom insoles that were specific to the participants' foot type, and the Insole and Exercise group $(n=10)$ followed the same exercise protocol as the Exercise group, but also used custom insoles. The researcher who participated in the intervention was not involved in the analysis of the data. All volunteers were given information about the study and provided their written, informed consent to participate.

At the start of the study, we collected anthropometric data (age, weight, height) and information about the type of leprosy. The evaluations of the volunteers' feet were based on the Semmes-Weinstein sensory test. The volunteers were considered eligible for the study if they did not respond to the $10 \mathrm{~g}$ monofilament stimuli on three or more plantar sites of each foot $t^{4}$.

Computerized photogrammetry was used to evaluate the results of the three treatments. This is a quantitative postural evaluation technique which has had its reliability and validity for evaluation of the feet assessed in the past ${ }^{16}$.

Few professionals routinely measure plantar pressures. Such measurements require specific technology that is prohibitively expensive. We, therefore, decided to base our classification on images of the biomechanical conformation of the foot acquired via podoscopy and photogrammetry ${ }^{17}$.

Before the treatments began, a photographic record of the forefoot, hindfoot, and plantar arch of each participant was made for future analysis with photogrammetry. The participants were positioned orthostatically on a Carci ${ }^{\circledR}$ podoscope with bipedal support. They were barefoot and had their legs bare up to the knees. A $0.075 \mathrm{~m}$ wide EVA rectangle was used to maintain a standard distance between the feet. The upper limbs were positioned parallel to the trunk, and the participants were instructed to stare at a horizontal point directly in front of them. Photos of the plantar arch, forefoot, and hindfoot of each participant in this position were taken using a digital camera positioned on a levelled tripod in front of the podoscope, in accordance with the standardized procedure suggested by Iunes ${ }^{17}$. To capture images of the plantar arch and hindfoot, the participants were photographed in the posterior frontal plane, and to capture images of the forefoot, they were photographed in the previous frontal plane. To capture images of the plantar arch, the camera was positioned approximately 30 degrees perpendicular to the podoscope's mirror, and to capture images of the forefoot and hindfoot, the camera was angled horizontally ${ }^{17}$. 


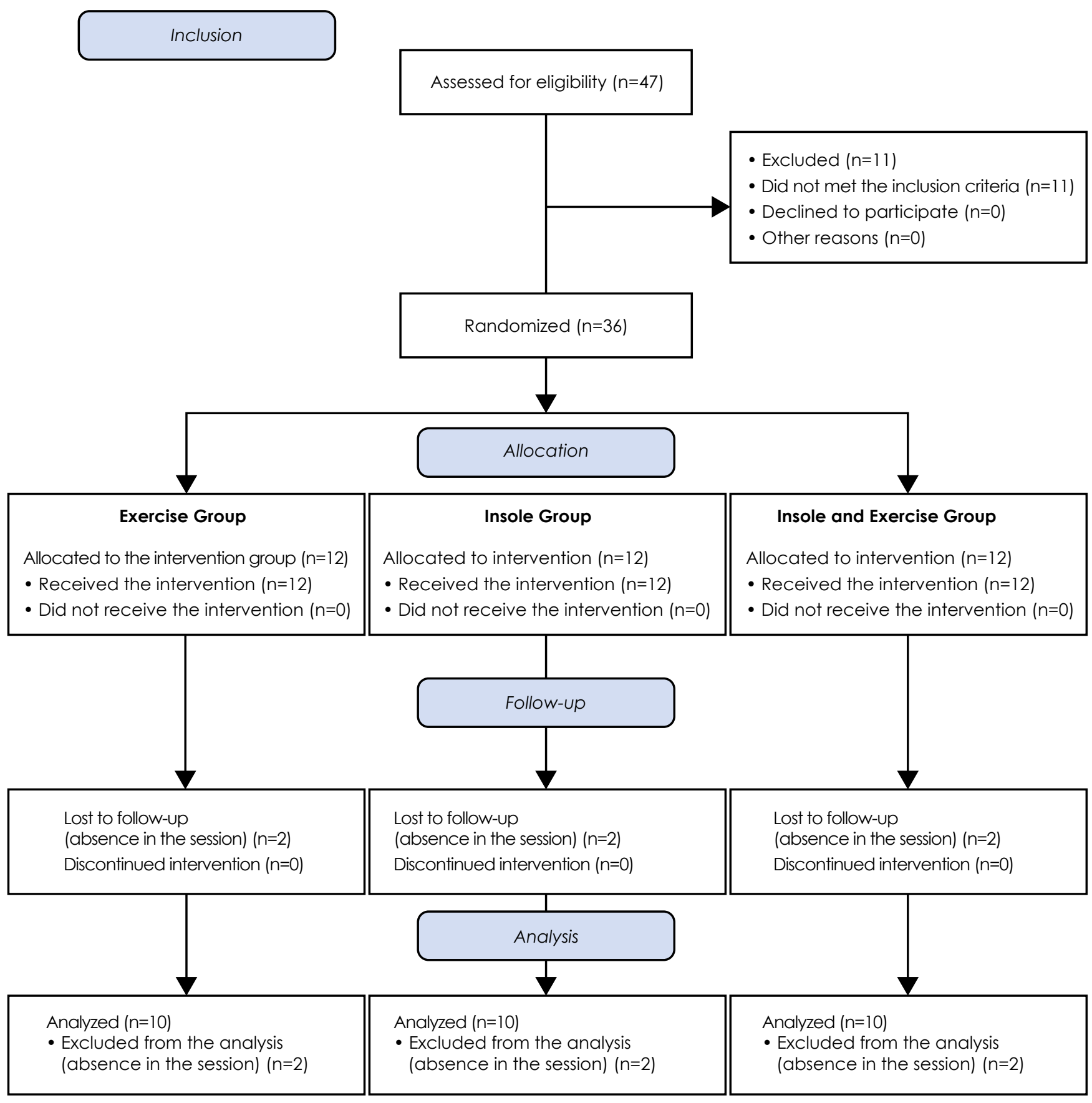

Figure 1. Flowchart showing sample size at all stages of the study

\section{Points marked on the volunteers}

The following anatomical points were marked on the lower members of the volunteers for further analysis by photogrammetry ${ }^{17}$. The heads of the first and fifth metatarsals, the posterior calcaneal tuberosity $(0.03 \mathrm{~m}$ support platform), a second point $0.04 \mathrm{~m}$ above it $(0.07 \mathrm{~m}$ support platform), a third point $0.13 \mathrm{~m}$ above the support surface, and the final point $0.22 \mathrm{~m}$ above the platform. The points were marked with white adhesive labels $\left(\operatorname{Pimaco}^{\circledR}\right)$,
$0.09 \mathrm{~m}$ in diameter. All photographs and demarcations of the anatomical points were respectively taken and performed by the same examiner.

\section{Treatments}

After the photographic records were made, the patients received different treatments according to which group they belonged. For the Exercise group, 20 sessions were held for 30 minutes twice a week, 
with exercises for the triceps surae, stretching for ankle mobility, and strengthening exercises for the intrinsic muscles of the feet based on the Incapacities Handbook of the Ministry of Health ${ }^{9}$ (Chart 1). The patients were instructed to perform the same exercises at home once a day.

The patients were evaluated based on the criteria of the Ministry of Health ${ }^{18}$. These criteria are divided into stages: gait assessment, evaluation of the hindfoot and forefoot, and production of a mold for the insole. For the Insole group, customized insoles adapted to each foot were produced, then used by the patients for four months (Figure 2).
The insoles were made from EVA using molds of the patients' feet, with metatarsal support or support for the plantar arch and heel, depending on each patient's needs. The insoles were sandpapered to ensure that the surface was completely homogeneous and that there were no protrusions that might cause injuries to the foot. The participants were instructed to replace the insoles of their favorite pairs of shoes with these insoles, and to use them for as long as possible during the day.

The Insole and Exercise group participated in 20 exercise sessions, exactly as the Exercise group did, and used specially adapted insoles for four months, as the Insole group did.

Chart 1. Exercises performed by the Exercise group and the Insole and Exercise group $p^{9,15}$

A) The stretching of the sural triceps muscle was performed with the patient standing before a wall in an orthostatic position, with one leg in front of the other, flexing one knee and keeping the entire rear foot resting on the ground in the dorsiflexion position. The posture is held for 30 seconds.

B) The exercise above is carried out, except the patient is instructed to keep both feet behind the body line and inclined toward the wall in front of him or her.

C) The patient sits with both feet flat on the floor, first performing maximum plantar flexion, then maximum dorsiflexion.
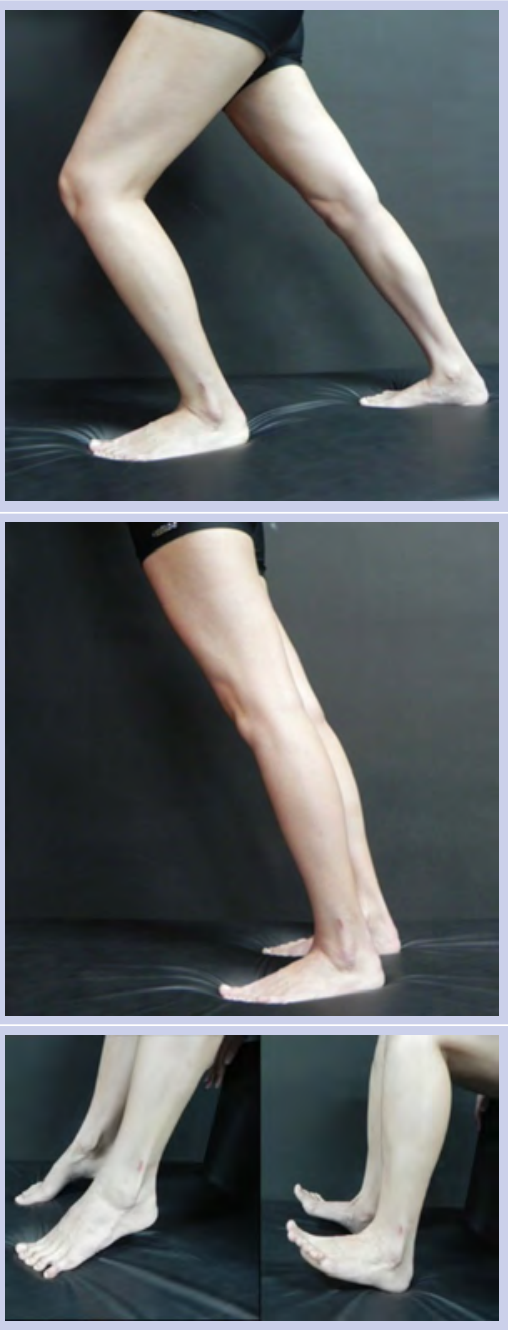

(continues) 
Chart 1. Continuation

D) The volunteer is instructed to remain seated and prompted to grab some marbles with his or her toes.

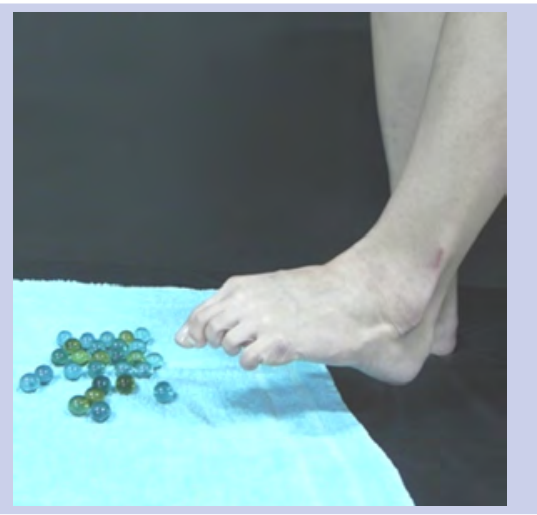

E) In the same position as the previous exercise, standing with his or her feet on a towel, the patient flexes his or her toes to displace and crumple up a towel.

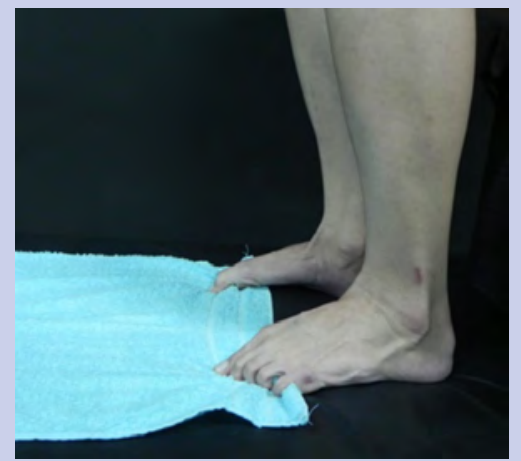

F) While lying in a supine position, the patient performs flexion and extension of the toes, plantar flexion, and ankle circumduction, to then perform a resistance exercise using an elastic band.

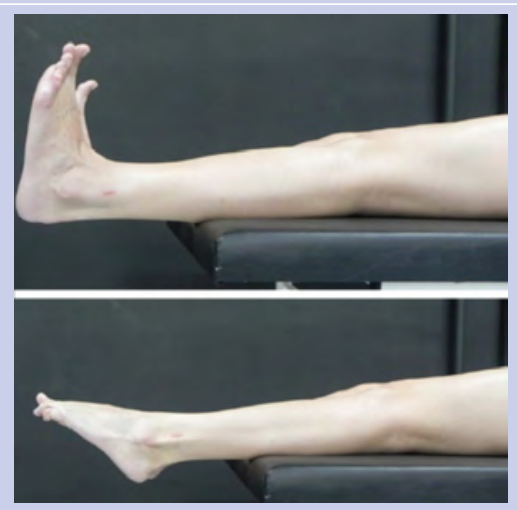

G) Lying in the supine position, like in the previous exercise, the patient performs the flexion and external rotation of the hip, knee flexion, and ankle dorsiflexion, followed by plantar flexion of the ankle, knee extension, and hip extension.

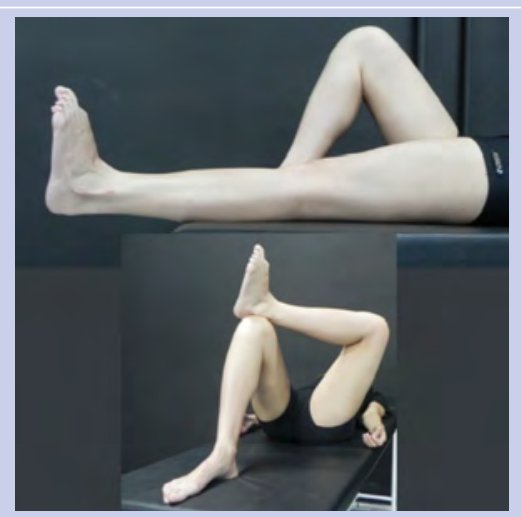

H) Finally, the patient performs a series of walking exercises, first walking on the heels, then the toes, then the sides of the feet. The distance walked is gradually increased.

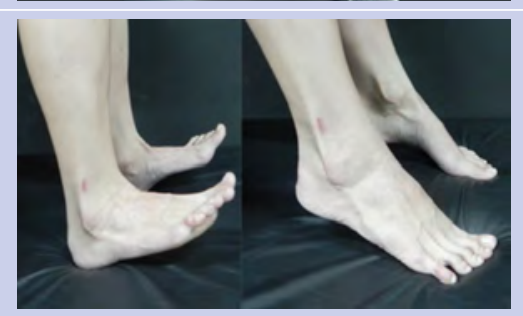




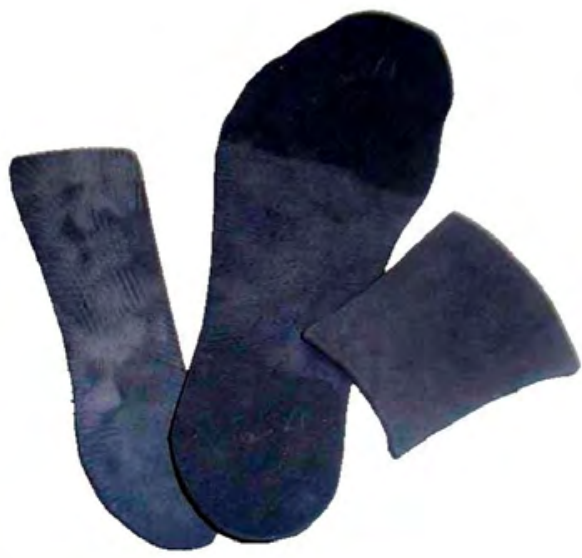

Figure 2. Insoles made from EVA

\section{Re-evaluation of the feet}

At the end of the treatment period, all the volunteers had their feet photographed again by the same photographer as before, using the same procedures and parameters as those used to make the baseline photographic records.

\section{Image analysis}

All the captured images were analyzed by a single examiner, and the pre- and post-treatment images were analyzed at the same time. The images were numbered and randomly ordered by a third investigator so that the examiner was blind to the group to which the images belonged. All images were analyzed three times, and a mathematical mean was used in subsequent analyses.

The analysis of the forefoot was carried out using the Alcimagem ${ }^{\circledR}$ software to trace a line from the head of the first metatarsal to the head of the fifth, and the horizontal plane. It was considered pronated when $<0^{\circ}$ (normal) < supinate $^{19}$.

The analysis of the hindfoot was also carried out using the Alcimagem ${ }^{\circledR}$ software. A line was traced from the first point $(0.03 \mathrm{~m})$ to the second $(0.07 \mathrm{~m})$, and a second line was traced from the highest point $(0.22 \mathrm{~m})$ to the point corresponding to $0.13 \mathrm{~m}^{17}$. The angle of intersection of the extensions of both lines was classified as follows: $05^{\circ}$ : normal tendon calcaneus; $<0^{\circ}$ : varus; $>5^{\circ}$ : valgus ${ }^{20}$.

The plantar-arch analysis was performed using the AutoCAD $2000{ }^{\circledR}$ software, as follows: we drew a horizontal line across the isthmus of the plantar arch and another horizontal line $b$ on the midpoint of the calcaneus. To determine the morphological mapping, according to Staheli et al. ${ }^{21}$, a straight "A" line was divided by the "B" line. If the values were smaller than $0.01 \mathrm{~m}$, the foot was considered normal. If they were higher than $0.01 \mathrm{~m}$, the foot was classified as a flat foot. A cavus foot measured below $0.003 \mathrm{~m}$ and was used as a reference measure.

\section{Statistical analyses}

The statistical analyses were performed using SPSS 20.0 for Windows. Data were expressed as mean \pm SD. The normality of the variables' distribution was assessed with the Kolmogorov-Smirnov test. Comparisons between groups related to the participants' characteristics (age, mass and height) were carried out using one-way ANOVA. The nominal categorical data (gender and leprosy type) were analysed by the chi-square test. Comparisons between groups and times (before and after treatment) were carried out using three-way ANOVA, followed by post hoc Bonferroni-correction tests. With the hindfoot as the main variable, a power effect of 0.95 and an effect size of $0.72(\alpha=0.05)$ were obtained with a sample size of 30 . The GPower ${ }^{\circledR} 3.1 .7$ software (Franz Faut, Universität Kiel Germany, 2008) was used for the analyses. The significance level was set at $p<0.05$ for all tests.

\section{RESULTS}

The characteristics of the participants in the three groups are shown in Table 1 . The results demonstrate that there is no statistical difference for the variables age, mass and height. The data on sex and types of leprosy do not show association with the type of treatment used because this may have occurred by mere chance.

The comparisons between groups revealed posttreatment changes in the positioning of the left hindfoot in the Exercise group and in the Insole group (Table 2), but there were no such changes in the Insole and Exercise group, demonstrating that the two features can modify the left hindfoot's alignment when used in isolation, but do not modify it when used in association.

No major effects were detected between groups or times for the forefoot and plantar arch. For the three angles assessed, no changes were identified between the three groups during the pre and the post moments when analyzed in isolation, that is, the groups were the same initially and remained the same after the interventions. 
Table 1. Characteristics of the participants

\begin{tabular}{|c|c|c|c|c|c|}
\hline Characteristics & & $\begin{array}{l}\text { Exercise } \\
(n=10)\end{array}$ & $\begin{array}{l}\text { Insole } \\
(n=10)\end{array}$ & $\begin{array}{l}\text { Insole and Exercise } \\
\qquad(n=10)\end{array}$ & $P$-Value \\
\hline Mass (kg) & & $73.31 \pm 15.09$ & $67.70 \pm 13.45$ & $68.28 \pm 8.72$ & $0.5952^{*}$ \\
\hline Height (m) & & $1.66 \pm 0.10$ & $1.65 \pm 0.09$ & $1.69 \pm 0.09$ & $0.6097^{*}$ \\
\hline \multirow{2}{*}{ Gender } & Female & 03 & 05 & 05 & \multirow{2}{*}{$0.581 \#$} \\
\hline & Male & 07 & 05 & 05 & \\
\hline \multirow{2}{*}{$\begin{array}{l}\text { Leprosy Type } \\
\text { Number of cases }\end{array}$} & Borderline & 6 & 7 & 7 & \multirow[t]{2}{*}{$0.984 \neq$} \\
\hline & Tuberculoid & 1 & 1 & 1 & \\
\hline
\end{tabular}

*: Anova; \#: chi-square.

Table 2. Means, standard deviations (mean $\pm \mathrm{SD}$ ), and confidence intervals $(\mathrm{Cl})$ for the measurements of the variables in the three groups before (pre) and after (post) treatment

\begin{tabular}{|c|c|c|c|c|c|}
\hline Right Foot & Groups & Pre & Post & Time & Time*Group \\
\hline \multirow{3}{*}{ Forefoot $\left({ }^{\circ}\right)$} & Exercise & $\begin{array}{r}9.23 \pm 3.66 \\
(6.61-11.85)\end{array}$ & $\begin{array}{r}10.11 \pm 3.63 \\
(7.51-12.70)\end{array}$ & \multirow{3}{*}{0.983} & \multirow{3}{*}{0.370} \\
\hline & Insole & $\begin{array}{r}9.89 \pm 2.05 \\
(8.34-11.44)\end{array}$ & $\begin{array}{r}9.70 \pm 2.82 \\
(7.69-11.72)\end{array}$ & & \\
\hline & Insole and Exercise & $\begin{array}{r}11.06 \pm 3.83 \\
(8.17-13.94)\end{array}$ & $\begin{array}{l}10.34 \pm 3.93 \\
(7.53-13.15)\end{array}$ & & \\
\hline \multirow{3}{*}{ Hindfoot $\left({ }^{\circ}\right)$} & Exercise & $\begin{array}{r}6.83 \pm 2.99 \\
(4.69-8.97)\end{array}$ & $\begin{array}{r}6.32 \pm 4.03 \\
(3.44-9.20)\end{array}$ & \multirow{3}{*}{0.963} & \multirow{3}{*}{0.687} \\
\hline & Insole & $\begin{array}{r}6.93 \pm 2.35 \\
(5.25-8.61)\end{array}$ & $\begin{array}{r}6.69 \pm 2.50 \\
(4.91-8.48)\end{array}$ & & \\
\hline & Insole and Exercise & $\begin{array}{r}5.10 \pm 3.18 \\
(2.83-7.38)\end{array}$ & $\begin{array}{r}5.78 \pm 3.32 \\
(3.40-8.15)\end{array}$ & & \\
\hline \multirow{3}{*}{ Plantar Arch (cm) } & Exercise & $\begin{array}{r}0.66 \pm 0.14 \\
(0.57-0.76)\end{array}$ & $\begin{array}{r}0.57 \pm 0.14 \\
(0.47-0.67)\end{array}$ & \multirow{3}{*}{0.116} & \multirow{3}{*}{0.089} \\
\hline & Insole & $\begin{array}{r}0.46 \pm 0.11 \\
(0.38-0.55)\end{array}$ & $\begin{array}{r}0.42 \pm 0.13 \\
(0.33-0.52)\end{array}$ & & \\
\hline & Insole and Exercise & $\begin{array}{r}0.53 \pm 0.14 \\
(0.43-0.63)\end{array}$ & $\begin{array}{r}0.56 \pm 0.17 \\
(0.44-0.68)\end{array}$ & & \\
\hline Left Foot & & Pre & Post & & \\
\hline \multirow{3}{*}{ Forefoot $\left({ }^{\circ}\right)$} & Exercise & $\begin{array}{r}6.47 \pm 2.32 \\
(4.71-8.20)\end{array}$ & $\begin{array}{r}7.10 \pm 3.19 \\
(4.82-9.39)\end{array}$ & \multirow{3}{*}{0.820} & \multirow{3}{*}{0.442} \\
\hline & Insole & $\begin{array}{r}6.78 \pm 3.46 \\
(4.17-9.35)\end{array}$ & $\begin{array}{r}6.38 \pm 2.62 \\
(4.51-8.27)\end{array}$ & & \\
\hline & Insole and Exercise & $\begin{array}{r}6.68 \pm 2.52 \\
(4.78-8.58)\end{array}$ & $\begin{array}{r}6.12 \pm 2.56 \\
(4.29-7.95)\end{array}$ & & \\
\hline \multirow{3}{*}{ Hindfoot $\left({ }^{\circ}\right)$} & Exercise & $\begin{array}{l}2.99 \pm 2.55^{A} \\
(1.17-4.81)\end{array}$ & $\begin{array}{l}6.30 \pm 3.22^{B} \\
(4.00-8.61)\end{array}$ & \multirow{3}{*}{0.001} & \multirow{3}{*}{0.472} \\
\hline & Insole & $\begin{array}{l}5.00 \pm 3.07^{A} \\
(2.80-7.20)\end{array}$ & $\begin{array}{l}6.38 \pm 3.05^{B} \\
(4.19-8.54)\end{array}$ & & \\
\hline & Insole and Exercise & $\begin{array}{r}4.19 \pm 3.26 \\
(1.85-6.53)\end{array}$ & $\begin{array}{r}6.58 \pm 4.14 \\
(3.62-9.52)\end{array}$ & & \\
\hline \multirow{3}{*}{ Plantar Arch (cm) } & Exercise & $\begin{array}{r}0.60 \pm 0.19 \\
(0.47-0.75)\end{array}$ & $\begin{array}{r}0.59 \pm 0.14 \\
(0.49-0.69)\end{array}$ & \multirow{3}{*}{0.069} & \multirow{3}{*}{0.863} \\
\hline & Insole & $\begin{array}{r}0.45 \pm 0.12 \\
(0.37-0.53)\end{array}$ & $\begin{array}{r}0.40 \pm 0.12 \\
(0.32-0.48)\end{array}$ & & \\
\hline & Insole and Exercise & $\begin{array}{r}0.52 \pm 0.12 \\
(0.43-0.61)\end{array}$ & $\begin{array}{r}0.48 \pm 0.15 \\
(0.38-0.59)\end{array}$ & & \\
\hline
\end{tabular}

Bonferroni test: different letters show statistical significance $(p<0.05)$ 


\section{DISCUSSION}

The treatment of people affected by leprosy should include measures for the prevention and rehabilitation of disabilities, with the aim of improving the patients' quality of life and preventing the emergence of other changes ${ }^{3}$.

Leg and feet exercises ${ }^{18}$ and insoles are important preventive and rehabilitative treatments ${ }^{8,9,18}$; but there are still few studies demonstrating their effectiveness ${ }^{6,8}$.

This study compared three treatments designed to promote changes in the alignment of the forefoot, hindfoot, and plantar arch. The results demonstrated that following a specific exercise protocol (Exercise group) and using custom insoles (Insole group) produced realignment of the left hindfoot, making it valgus. These findings are not consistent with other research showing that guided exercise can produce improvements in movement, alignment, and sensitivity in patients with neuropathic feet due to leprosy ${ }^{22}$. It has been recommended that when changes in sensitivity and leg alignment are detected in leprosy cases, a custom EVA insole should be used to decrease the pressure on peak-pressure areas and prevent plantar ulcers ${ }^{8,18}$. In the present study, the peak pressure on the plant region of the patients' feet was not analyzed. Tang et al. $^{8}$ demonstrates that the use of customized insoles is capable of reducing the pressures on the regions of the bilateral heels, on the left middle-lateral region, from the second to the fourth bilateral metatarsus, and on the fifth left metatarsus. As observed in the previous study, the left forefoot and hindfoot were the ones that most experienced pressure alterations, and the data found are similar to the alignment changes presented here. It is possible that the exercise protocol and the insole, when used in isolation, can alter the pressures on the plantar region, but further studies should be developed. The insole, when in contact with the plant of the foot, alters the gait pattern controlling foot pressure and movement in the ankle joint ${ }^{23}$.

The effects of treatment for neuropathic plantar ulcers on the feet are already well-established. However, the evidence on the effects of using insoles and specific exercise protocols is not conclusive ${ }^{6}$, and these treatments are not well-standardized ${ }^{24}$.

Several studies have investigated whether using prescription shoes and insoles designed to redistribute plantar pressure can prevent the recurrence of ulcers ${ }^{8,22,25}$. A study by Seboka and Alert ${ }^{25}$ showed that shoes made of canvas could prevent the formation of ulcers in leprosy patients and that the cost-benefit ratio for treatment was good. Other authors ${ }^{8}$ have asserted that wearing custommade shoes and insoles increases the contact area between foot and shoe, thereby decreasing peak plantar pressure. The results evidenced in the present study demonstrate the possibility of alteration of the left foot's pressure points, since there was a change in the alignment of the hindfoot which is associated with the reduction in the heel pressure evidenced in other studies ${ }^{8}$. In addition, an asymmetric distribution typical of leprosy ${ }^{26}$ could be involved in the patients evaluated, but this datum was not collected. This alteration commonly leads to multiple mononeuritis which in turn can lead to different results between the feet ${ }^{26}$. Thus, there is a need for broader studies to determine the sensitivity and specificity of clinical determinants, such as photogrammetric analysis for screening purposes in daily practice.

Another factor that may have occurred was the negligence on the part of the study participants regarding the use of insoles. Our finding of change in the left hindfoot's alignment with the use of insoles in only one foot suggests that some patients neglected the use of the insoles or did not use them as directed. One study reported that $42.4 \%$ of insole users do not adhere to treatment due to difficulties in adapting to the change in footwear ${ }^{27}$.

In other conditions that induce neuropathic changes in the foot, such as diabetes, it has been demonstrated that the use of insoles and adapted shoes decreases plantar pressure $^{28}$. Although diabetes and leprosy are different diseases, the mechanical factors affecting the neuropathic foot are very similar ${ }^{15,28}$. Our findings are consistent with previous results of the use of prescription insoles to reduce pressure points, as we have demonstrated the left hindfoot's realignment following the use of custom insoles.

The exercise-only treatment also promoted changes in the alignment of the left hindfoot, making it valgus; however, when this treatment was combined with the use of insoles, no such change was found. It has been shown that the patients with neuropathy due to leprosy who had undergone treatment with exercise and/or guidelines showed improvement ${ }^{22}$, but currently, it has been suggested that only exercises for the hands and eyes are recommended for these patients ${ }^{15}$. We believe that exercises for the lower limbs as a whole, not only the feet, should be included in programs to prevent disability in patients with leprosy, as they can improve local blood circulation, as well as produce changes in the feet's alignment. When the use of insoles is prescribed, patients should be educated about their benefits and the 
correct way of using them. In the case of the association of insole and exercise, follow-up for more than four months may be necessary to achieve good clinical results. We believe that the follow-up period was not enough to identify significant alterations in that group.

In this study, we were unable to ensure that the insoles were used correctly, as providing free insoles and guidance on how to use them does not guarantee that they will be used correctly. This is one limitation of our study ${ }^{27}$. The other limitation is the lack of a control group and the allocation by convenience. In addition, we did not take any quantitative measurements of the pressure exerted on the skin of the feet's plantar region, so this should be the subject of further research.

Given the above, the alignment of the left hindfoot can be changed with supervised exercises or the use of insoles, but these treatments did not affect the alignment of the forefoot and of the plantar arch. We also found that combining exercise and insoles did not alter the alignment of the feet during the study's evaluation period, which suggests that follow-up for more than four months may be needed.

\section{REFERENCES}

1. World Health Organization. Global leprosy: update on the 2012 situation. Weekly Epidemiological Record. 2013;88(35):365-80.

2. World Health Organization. Global leprosy strategy 2016-2020: accelerating towards a leprosy-free world. 2016 [cited 2017 June 2]. Available from: https://bit.ly/2bB7J1R.

3. World Health Organization. Global leprosy update, 2015: time for action, accountability and inclusion. Weekly Epidemiological Record. 2016;(91)35:405-20.

4. Brasil. Ministério da Saúde. Prevalência de hanseníase. 2012 [cited 2017 June 2]. Available from: https://bit.ly/2RXKntC

5. World Health Organization. Enhanced global strategy for further reducing the disease burden due to leprosy (plan period: 2011-2015). 2009 [cited 2015 Dec. 15]. Available from: https://bit.ly/2NBch03

6. Cordeiro TL, Barros ARSB, Foss NT, Frade MAC. Prospective evaluation of leprosy patients wearing insole. J Neurol Neurosci. 2015;6:1-5. doi: 10.21767/2171-6625.S10008

7. Slin FJ, Keukenkamp R, Schie CH, Faber WR, Nollet F. Foot impairments and limitations in walking activities in people affected by leprosy. J Rehabil Med. 2011;43(1):32-8. doi: 10.2340/16501977-0625

8. Tang SF, Chen CP, Lin SC, Wu CK, Chen CK, Cheng SP. Reduction of plantar pressures in leprosy patients by using custommade shoes and total contact insoles. Clin Neurol Neurosurg. 2015;129(Suppl. 1):S12-5. doi: 10.1016/S0303-8467(15)30005-6

9. Brasil. Ministério da Saúde. Manual de prevenção de incapacidades. Brasília, DF: Ministério da Saúde; 2008 [cited 2019 June 4]. Available from: https://bit.ly/2XvfBhC
10. Cheung JTM, Zhang M. Parametric design of pressurerelieving foot orthosis using statistics-based finite element method. Med Eng Phys. 2008;30(3):269-77. doi: 10.1016/j. medengphy.2007.05.002

11. Veen NHJ, Mcnamee P, Richardus JH, Smith WCS. Costeffectiveness of interventions to prevent disability in leprosy: a systematic review. PLoS ONE. 2009;4(2):e4548. doi: 10.1371/ journal.pone.0004548

12. Warren G. The foot in leprosy: lessons for diabetes. In: Boulton AJM, Connor H, Cavanagh PR. The foot in diabetes. Chichester: John Wiley \& Sons; 2007. p. 345-362.

13. Schie CHM. A review of the biomechanics of the diabetic foot. Int J Low Extrem Wounds. 2005;4(3):160-70. doi: $10.1177 / 1534734605280587$

14. Lee E, Cho J, Lee S. Short-foot exercise promotes quantitative somatosensory function in ankle instability: a randomized controlled trial. Med Sci Monit. 2019;25:618-26. doi: 10.12659/ MSM.912785

15. Wim Brandsma J. Rehabilitation of leprosy-affected people: an overview. Clin Dermatol. 2016;34(1):66-9. doi: 10.1016/j. clindermatol.2015.10.015

16. Iunes DH, Bevilaqua-Grossi D, Oliveira AS, Castro FA, Salgado HS. Comparative analysis between visual and computerized photogrammetry postural assessment. Braz J Phys Ther. 2009;13(4):308-15. doi: 10.1590/S1413-35552009005000039

17. Iunes DH, Carmélia BJ, Rocha CBJ, Borges NCS, Marcon CO, Pereira VM, et al. Self-care associated with home exercises in patients with type 2 diabetes mellitus. PLOS ONE. 2014;9(12):e114151. doi: 10.1371/journal.pone.0114151

18. Brasil. Ministério da Saúde. Manual de adaptações de palmilhas e calçados. Brasília, DF: Ministério da Saúde; 2008 [cited 2019 June 5]. Available from: https://bit.ly/2YxLaE9

19. Hamill J, Knutzen KM, Derrick TR. Biomechanical basis of human movement. USA: Lippincott Williams and Wilkins; 2015

20. Kapandji Al. The physiology of the joints: lower limb. London: Churchill Livingstone; 2010.

21. Staheli LT, Chew DD, Corbett MT. The longitudinal arch. A survey of eight hundred and eighty-two feet in normal children and adults. J Bone Joint Surg Am. 1987;69(3):426-8.

22. Gonçalves SD, Sampaio RF, Antunes CMF. Predictive factors of disability in patients with leprosy. Rev Saúde Publica. 2009;43(2):267-74. doi: 10.1590/S0034-89102009000200007

23. Kim SH, Ahn SH, Jung GS, Kim JH, Cho YW. The effects of biomechanical foot orthoses on the gait patterns of patients with malalignment syndrome as determined by three dimensional gait analysis. J Phys Ther Sci. 2016;28(4):118893. doi: 10.1589/jpts.28.1188

24. Hutchins S, Bowker P, Geary N, Richards J. The biomechanics and clinical efficacy of footwear adapted with rocker profiles evidence in the literature. Foot. 2009;19(3):165-70. doi: 10.1016/j. foot.2009.01.001

25. Seboka G, Alert PS. Cost-effective footwear for leprosy control programmes: a study in rural Ethiopia. Lepr Rev. 1996;67:208-16.

26. Slim FJ, Schie CH, Keukenkamp R, Faber WR, Nollet F. Increased plantar foot pressure in persons affected by leprosy. Gait Posture. 2012;35(2):218-24. doi: 10.1016/j.gaitpost.2011.09.010 
27. Guimarães CQ, Teixeira-Salmela LF, Rocha IC, Bicalho LI, Sabino GS. Factors related to compliance with biomechanical insole use. Braz J Phys Ther. 2006;10(3):271-7. doi: 10.1590/ S1413-35552006000300004
28. Boulton, AJM. Diabetic foot - what can we learn from leprosy? Legacy of Dr. Paul W. Brand. Diabetes Metab Res Rev. 2012;28(Suppl. 1):3-7. doi: 0.1002/dmrr.2230. 